\title{
Synthesis and characterization of styrene-co-divinylbenzene-graft-linseed oil by free radical polymerization
}

\author{
V. Sharma ${ }^{1,2}$, J. S. Banait ${ }^{2}$, R. C. Larock ${ }^{3}$, P. P. Kundu ${ }^{*}$ \\ ${ }^{1}$ Department of Chemical Technology, Sant Longowal Institute of Engineering \& Technology, Sangrur, Punjab-148106, \\ India \\ ${ }^{2}$ Department of Chemistry, Punjabi University, Patiala, Punjab-147002, India \\ ${ }^{3}$ Department of Chemistry, Iowa State University, Ames, Iowa 50011, USA
}

Received 1 January 2008; accepted in revised form 27 February 2008

\begin{abstract}
A variety of opaque white to light yellow polymeric material have been prepared by two methods, one copolymerization of styrene (ST), divinylbenzene (DVB), and grafting of linseed oil (LIN), and the second involves the copolymerization of the same comonomers with pre-reacted (with initiator) linseed oil. All of the reactant mixtures in different concentrations start to solidify at $100^{\circ} \mathrm{C}$ and give rise to a solid crosslinked polymer at $130^{\circ} \mathrm{C}$. These polymeric materials contain approximately 30 to $74 \%$ of crosslinked materials. Their ${ }^{1} \mathrm{H}$ NMR spectra indicate that the polymeric samples contain both soft oily and hard aromatic segments. The insoluble material left after soxhlet extraction contains finely distributed micropores. The heat deflection temperatures (HDT) of the polymer samples range from 26 to $44^{\circ} \mathrm{C}$. The glass transition temperature for different linseed oil polymer samples ranges from 66 to $147^{\circ} \mathrm{C}$ (from dynamic mechanical analysis) and 158 to $182^{\circ} \mathrm{C}$ (from differential scanning calorimetry). The crosslinking density of samples ranges from 35.0 to $6.01 \cdot 10^{4} \mathrm{~mol} / \mathrm{m}^{3}$. Irrespective of methods, the storage modulus decreases with increasing oil content in the copolymers. The polymers prepared by the first method show minimum swelling in saline water and maximum swelling in tetrahydrofuran. On the other hand, the polymers from the second method show maximum swelling in alkaline solution and a minimum in acidic solution.
\end{abstract}

Keywords: biopolymers, linseed oil, swelling ratio, copolymerization, transition temperature

\section{Introduction}

Linseed oil is a triglyceride oil consisting mainly of linolenic acid (53\%), oleic acid (18\%), linoleic acid (15\%), palmitic acid (6\%) and stearic acid (6\%) [1]. Linseed oil is considered a good drying oil, used mainly for the preparation of paints and varnishes [2]. It is also used in enamels, linoleum, oilcloth, patent leather, printer's ink and as waterproofing for raincoats, slickers and tarpaulins [3].

Considerable research has been carried out on applications of linseed oil. In medicinal front, it is claimed that linseed oil is useful in treating anxiety, prostate problems, vaginitis, weight loss and certain types of cancer [4], but appropriate research is lacking. To improve its film properties, different olefinic monomers, such as styrene, have been copolymerized with linseed oil [5-7]. Recently, it has been reported [8] that the reaction of styrene with drying oils depends on the number of conjugated double bonds present in the drying oil. Larock and coworkers have successfully prepared useful bioplastics from tung [9] and linseed oil [10]

*Corresponding author, e-mail: ppk923@yahoo.co.in

(C) BME-PT and GTE 
by thermal copolymerization. Some bioplastics have also been prepared from soybean [11, 12], tung [13], and corn [14] oils by cationic copolymerization with varying amounts of styrene (ST) and divinylbenzene (DVB). Crosslinked bacterial polyesters have been obtained by the free radical polymerization of soybean oil acids [15]. Extensive research has been devoted to the development of polymers from triglyceride oils as a natural alternative to petroleum-based polymers [16-18]. In this work, common linseed oil is grafted free radically with ST and DVB to prepare a range of promising new polymers.

\section{Materials and methods}

\subsection{Materials used}

The linseed oil (LIN) used in this study was purchased from the local market. ST and DVB (stabilized with 4-tert-butylpyrocatechol) were purchased from Merck Chemical Co., Germany and used as received. Benzoyl peroxide (BPO) was purchased from CDH Ltd., New Delhi (India) and used as received. Tetrahydrofuran was purchased from Merck Chemical Co., Germany and used as a solvent for extraction.

\subsection{Polymer preparation}

The polymeric materials have been prepared by heating the desired concentration of linseed oil [LIN or Benzoyl peroxide initiated Linseed Oil (BLO)], ST and DVB in a glass vial. Two different methods for preparation of the polymeric materials have been adopted. In the first method, all of the materials were mixed in a vial in the desired amounts, stirred thoroughly and then the initiator BPO (1\%) was added with stirring for proper dissolution. The material was heated sequentially to the desired temperatures for the appropriate amount of time, usually $85^{\circ} \mathrm{C}$ for 45 minutes, $100^{\circ} \mathrm{C}$ for 12 hours, $120^{\circ} \mathrm{C}$ for 24 hours and finally $130^{\circ} \mathrm{C}$ for 3 hours. When using the second method, the LIN was heated with $1 \% \mathrm{BPO}$ at $120^{\circ} \mathrm{C}$ for five hours (henceforth known as BLO) and then ST and DVB were added to the oil and heated sequentially to the desired temperatures, usually $85^{\circ} \mathrm{C}$ for 45 minutes, $100^{\circ} \mathrm{C}$ for 12 hours, $120^{\circ} \mathrm{C}$ for 24 hours and finally $130^{\circ} \mathrm{C}$ for 3 hours. The nomenclature used in this work is based on the original composition of the reactants. For example, LIN30-ST42-DVB28 represents a polymer prepared from 30 weight $\%$ of linseed oil (LIN), 42 weight $\%$ of ST and 28 weight $\%$ of DVB and BLO30-ST42-DVB28 represents a polymer prepared from 30 weight $\%$ of initiated linseed oil (BLO), 42 weight $\%$ of ST and 28 weight $\%$ of DVB.

\section{Characterization}

\subsection{Soxhlet extraction}

The polymeric materials reported in Table 1 were subjected to soxhlet extraction to determine their soluble and insoluble contents. About 2 gram sample of the bulk polymer was extracted for 24 hours with $150 \mathrm{ml}$ of refluxing tetrahydrofuran using a soxhlet extractor. After extraction, the resulting solution was concentrated by rotary evaporation and subsequently dried under vacuum. The insoluble materials were dried under vacuum for several hours before weighing.

\section{2. ${ }^{1} \mathrm{H}$ nuclear magnetic resonance spectroscopy ( ${ }^{1} \mathrm{H}$ NMR)}

The soluble extract from the polymeric material, as well as LIN, ST and DVB were dissolved in $\mathrm{CDCl}_{3}$. Tetramethylsilane (TMS) was used as a reference to compare the spectra obtained. The spectra were obtained using a multinuclear FT-NMR Spectrometer (Bruker AC-300 F) at $300 \mathrm{MHz}$. A total of 30 scans were averaged to obtain the final data.

\subsection{Dynamic mechanical analysis (DMA)}

The dynamic mechanical analysis of the properties of bulk polymers were conducted by using a Perkin-Elmer dynamic mechanical analyzer DMA Pyris-7e in a three-point bending mode with a $110 \mathrm{mN}$ static force and a $110 \mathrm{mN}$ dynamic force. A rectangular specimen was prepared by machining the cylindrical product (obtained from heating in a vial) to specimens of $1.2-2 \mathrm{~mm}$ thickness and $5 \mathrm{~mm}$ depth. Each specimen was first cooled under liquid nitrogen to ca. $-60^{\circ} \mathrm{C}$, and then heated at $3^{\circ} \mathrm{C} / \mathrm{min}$ and at a frequency of $1 \mathrm{~Hz}$ under nitrogen. The viscoelastic properties, i.e. storage modulus $E^{\prime}$, and mechanical loss factor (damping) tan $\delta$ were recorded as a function of temperature. The glass transition temperature $T_{g}$ of the polymer was 
Table 1. Compositions of the crosslinked linseed oil-ST-DVB copolymers from soxhlet extraction and ${ }^{1} \mathrm{H}$ NMR spectroscopic studies

\begin{tabular}{|c|c|c|c|c|c|}
\hline \multirow{2}{*}{ Sample } & \multirow{2}{*}{ Polymer } & \multicolumn{2}{|c|}{ Soluble extracts a } & \multicolumn{2}{|c|}{ Soxhlet results } \\
\hline & & $\begin{array}{l}\text { Weight \% } \\
\text { of oil }\end{array}$ & $\begin{array}{c}\text { Weight\% } \\
\text { of ST and DVB }\end{array}$ & $\begin{array}{c}\text { Soluble }^{b} \\
\text { [wt\%] }\end{array}$ & $\begin{array}{c}\text { Insoluble }^{c} \\
\text { [wt\%] }\end{array}$ \\
\hline $\mathrm{C}_{1}$ & LIN30-ST42-DVB28 & 97.25 & 2.75 & $26.1(25.38 \mid 0.72)$ & $73.9(4.62 \mid 69.28)$ \\
\hline $\mathrm{C}_{2}$ & LIN35-ST39-DVB26 & 98.48 & 1.52 & $33.6(33.09 \mid 0.51)$ & $66.4(1.91 \mid 64.49)$ \\
\hline $\mathrm{C}_{3}$ & LIN40-ST36-DVB24 & 97.33 & 2.67 & $38.8(37.76 \mid 1.04)$ & $61.2(2.24 \mid 58.96)$ \\
\hline $\mathrm{C}_{4}$ & LIN45-ST33-DVB22 & 98.27 & 1.73 & $45.1(44.22 \mid 0.89)$ & $54.9(0.88 \mid 64.11)$ \\
\hline $\mathrm{C}_{5}$ & LIN50-ST30-DVB20 & 97.80 & 2.20 & $49.5(48.41 \mid 1.09)$ & $51.5(1.59 \mid 48.91)$ \\
\hline $\mathrm{C}_{6}$ & LIN55-ST27-DVB18 & 97.68 & 2.32 & $54.1(52.84 \mid 1.26)$ & $45.9(2.16 \mid 43.74)$ \\
\hline $\mathrm{C}_{7}$ & LIN60-ST24-DVB16 & 97.34 & 2.66 & $59.9(58.31 \mid 1.59)$ & $40.1(1.69 \mid 38.41)$ \\
\hline $\mathrm{C}_{8}$ & LIN65-ST21-DVB14 & 98.93 & 1.07 & $63.4(62.72 \mid 0.68)$ & $36.6(2.28 \mid 34.32)$ \\
\hline $\mathrm{B}_{1}$ & BLO30-ST42-DVB28 & 94.59 & 5.41 & $30.3(28.39 \mid 1.91)$ & $69.7(1.61 \mid 68.09)$ \\
\hline $\mathrm{B}_{2}$ & BLO35-ST39-DVB26 & 91.24 & 8.76 & $38.7(34.47 \mid 4.23)$ & $61.3(0.53 \mid 60.77)$ \\
\hline $\mathrm{B}_{3}$ & BLO40-ST36-DVB24 & 91.93 & 8.07 & $43.5(39.55 \mid 3.95)$ & $56.5(0.45 \mid 56.05)$ \\
\hline $\mathrm{B}_{4}$ & BLO45-ST33-DVB22 & 90.62 & 9.38 & 48.5(43.95 | 4.55) & $51.5(1.05 \mid 50.45)$ \\
\hline $\mathrm{B}_{5}$ & BLO50-ST30-DVB20 & 88.61 & 11.39 & $55.6(49.21 \mid 6.39)$ & $44.4(0.79 \mid 43.61)$ \\
\hline $\mathrm{B}_{6}$ & BLO55-ST27-DVB18 & 92.05 & 7.95 & $59.5(54.77 \mid 4.73)$ & $40.5(0.23 \mid 40.27)$ \\
\hline $\mathrm{B}_{7}$ & BLO60-ST24-DVB16 & 86.23 & 13.77 & $68.3(58.90 \mid 9.40)$ & $31.7(1.10 \mid 30.60)$ \\
\hline $\mathrm{B}_{8}$ & BLO65-ST21-DVB14 & 91.86 & 8.14 & $70.2(64.49 \mid 5.71)$ & $29.8(0.51 \mid 29.29)$ \\
\hline
\end{tabular}

aMicrocomposition of the extracted soluble materials calculated from the ${ }^{1} \mathrm{H}$ NMR spectra of the glyceride peak at $4.1 \mathrm{ppm}$ and the aryl $\mathrm{CH}$ peak at $7 \mathrm{ppm}$. ${ }^{\mathrm{b}}$ The data in parentheses have been calculated directly from the wt $\%$ of oil and wt $\%$ of aromatics in the soluble extract. The first value in the parentheses represents the $\%$ oil content and the second value represents the $\%$ aromatic content. ${ }^{c}$ The data in the parentheses have been calculated indirectly from the wt $\%$ of the oil and aromatic content in the soluble extract, as the total mass of the soluble and insoluble portions are held constant. The first value in the parentheses represents the \% oil content and the second value represents the $\%$ aromatic content.

obtained from the peak of the loss tangent plot. The crosslink densities, $v_{e}$, were determined from the rubbery modulus plateau based on the theory of rubber elasticity (Equation (1)) [19, 20]:

$E^{\prime}=3 v_{e} R T$

where $E^{\prime}$ is the storage modulus (Young's) of crosslinked polymer in the plateau region, $\mathrm{R}$ is the universal gas constant $\left(8.314 \mathrm{~J} \cdot \mathrm{mole}^{-1} \cdot \mathrm{K}^{-1}\right)$ and $T$ is the absolute temperature $[\mathrm{K}]$.

Since the three point bending mode was used for all dynamic measurements, the storage modulus obtained is a flexural modulus, which is related to Young's modulus as Equation (2) [21, 22]:

$E^{\prime}=\frac{12 D^{\prime}\left(1-v^{2}\right)}{h^{3}}$

where $D^{\prime}$ is the flexural storage modulus (flexural rigidity) per unit width; $v$ is Poisson's ratio and $h$ is the thickness of the specimen. For simplicity and ease of comparison with the previously published results [11], Equation (1) has been used to calculate the crosslink density, assuming that $E^{\prime}$ and $D^{\prime}$ are equal.

\subsection{Differential scanning calorimetry (DSC)}

Differential scanning calorimetric studies were carried out by using a differential scanning calorimeter (TA Instruments DSC Q10 V9.0 Build 275) in the temperature range of 35 to $250^{\circ} \mathrm{C}$ at a heating rate of $20^{\circ} \mathrm{C} / \mathrm{min}$. The sample weight used was approximately $4-5 \mathrm{mg}$. The peaks were used to determine the glass transition temperature $T_{g}$ of the samples which is approximately 20 to $40^{\circ} \mathrm{C}$ higher than $T_{g}$ shown by loss tangent plot. The area in $\mathrm{J} / \mathrm{gm}$ was also reported by integrating the peak from DSC results and peak width was calculated from the difference between starting point and finishing point of the DSC peak for each sample.

\subsection{Scanning electron microscopy (SEM)}

The polymeric samples to be scanned were mounted onto the specimen stub. The samples were sputter coated with a thin layer (approximately $25 \mathrm{~nm}$ ) of gold under a vacuum by using a JEOL Sputter 
Coater (JFM 1100). The metal coating prevents the buildup of high voltage charges on the specimen. In addition, the metal coatings serve as an excellent source of secondary electrons, as well as helping to disperse potentially damaging heat. The coated samples were examined using a JOEL scanning electron microscope (JSM 6100) at a $20 \mathrm{kV}$ accelerating voltage and the images were recorded on 120 B and W Roll Film (100 ASA).

\subsection{Heat deflection temperature (HDT)}

The heat deflection temperatures of the polymeric samples were measured according to ASTM D 648. The dimensions of the samples were $80 \times 10 \times 4 \mathrm{~mm}$. They were tested in a flatwise position. For the HDT measurements, the samples were heated from room temperature to $170^{\circ} \mathrm{C}$ at a rate of $2^{\circ} \mathrm{C}$ per minute. A load of $450 \mathrm{kPa}$ was applied to the sample at the center. Once the sample was deflected by $0.25 \mathrm{~mm}$, the temperature was noted. This is the heat deflection temperature (HDT) of the sample.

\subsection{Swelling analysis}

The swelling analyses of the polymeric samples were carried out in different solvents viz., saline $(20 \% \mathrm{NaCl})$, alkaline $(2 \% \mathrm{NaOH})$, acidic $(2 \%$ $\mathrm{H}_{2} \mathrm{SO}_{4}$ ) and tetrahydrofuran. To study the swelling kinetics, the so-called pat-and-weight technique was used for liquid sorption [23]. The polymeric samples were allowed to remain in the solution for 72 hours at room temperature and then weighed as soon as they were removed from the solvent. The samples were weighed after 2, 4, 8, 12, 24, 48 and 72 hours. The swelling ratio, $q_{v}$, of the various polymers at equilibrium [24] was determined using the Equation (3):

$q_{v}=\frac{\text { volume of swollen polymer }}{\text { volume of dry polymer }}$

\section{Results and discussion}

\subsection{Microstructure of the LIN-ST-DVB copolymers}

Sixteen polymer samples, in total, were prepared by the free radically grafted copolymerization of varying amounts of LIN, ST and DVB as reported in Table 1. The possible initiation reactions for this free radical process are shown in Figure 1. It is observed that the LIN employed in this study is oligomerized on heating and becomes viscous at $160^{\circ} \mathrm{C}$ or higher. No crosslinked polymers are evident at $160^{\circ} \mathrm{C}$, but upon standing for several days at room temperature, this oil forms an upper solid surface. This indicates that the LIN polymerizes in the presence of oxygen. Thus, the formation of crosslinked homopolymers from LIN probably depends on the conditions employed, namely the thickness of the surface layer, the temperature and the time of reaction with surface oxygen, etc. It is also observed that when this heated oil is mixed with equal amounts of ST and left for some days at room temperature, it also forms a solid upper surface. Thus, in order to get a viable product of considerable strength within some stipulated time, it is important that one mixes the LIN with some more thermally active reactants, like ST and DVB.

The activation temperature for the free radical copolymerization of ST and DVB is much lower than that of LIN. Both ST and DVB undergo polymerization at $100^{\circ} \mathrm{C}$, resulting in hard rigid solid material. Based on the above findings, the mixture of LIN, ST and DVB was successively heated at $85^{\circ} \mathrm{C}$ for 45 minutes, then $100^{\circ} \mathrm{C}$ for 12 hours, $120^{\circ} \mathrm{C}$ for 24 hours, and finally at $130^{\circ} \mathrm{C}$ for 3 hours. During the heating at $100^{\circ} \mathrm{C}$, all of the reactant mixtures $\left(\mathrm{C}_{1}-\mathrm{C}_{8}\right.$ and $\mathrm{B}_{1}-\mathrm{B}_{8}$ of Table 1$)$ solidified within two hours of heating. Thus, a reasonable mechanism for initiation may involve formation of the radicals $\mathbf{2}$ and $\mathbf{3}$ from ST and DVB after decomposition of the initiator. These radicals are then capable of attacking the $\mathrm{C}=\mathrm{C}$ bonds of the ST, DVB and LIN. After post curing at $130^{\circ} \mathrm{C}$, almost all of the starting materials are converted into crosslinked polymers. It is expected that the radicals $\mathbf{2}$ and $\mathbf{3}$ generated as shown in Figure 1 will form relatively stable radicals by adding either to ST or DVB. During prolonged heating, the STDVB copolymer chains crosslink at the pendant vinylic double bonds and the rest of the pendant vinylic double bonds react with many unreacted of double bonds in the LIN, leading to a crosslinked polymer having two distinctly separated soft and hard phases. The radical $\mathbf{5}$ is more pronounced and may result in grafting (6) of LIN in the ST-DVB polymer chain. The soft phase is comprised mainly of the LIN copolymer, whereas the hard phase con- 
A. Decomposition of Initiator:<smiles>[R][10PH]</smiles>
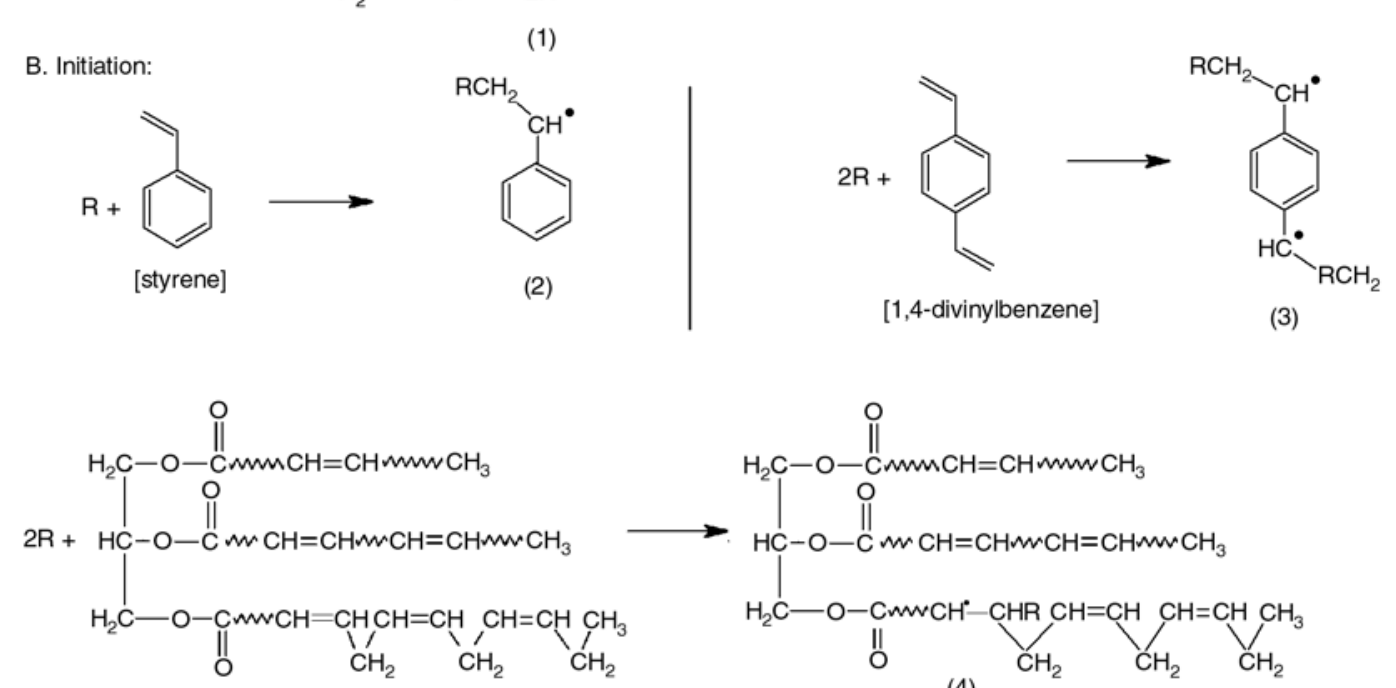

(4)

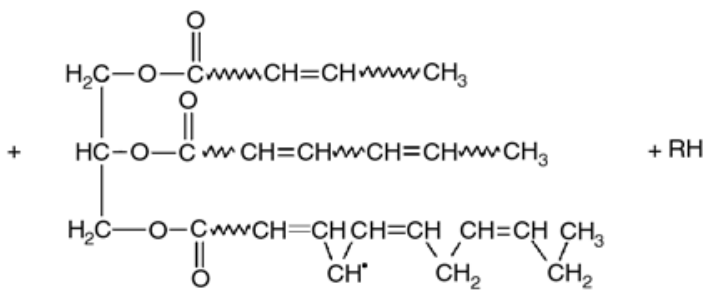

(5)

C. Grafting of Oil in ST - DVB Network:
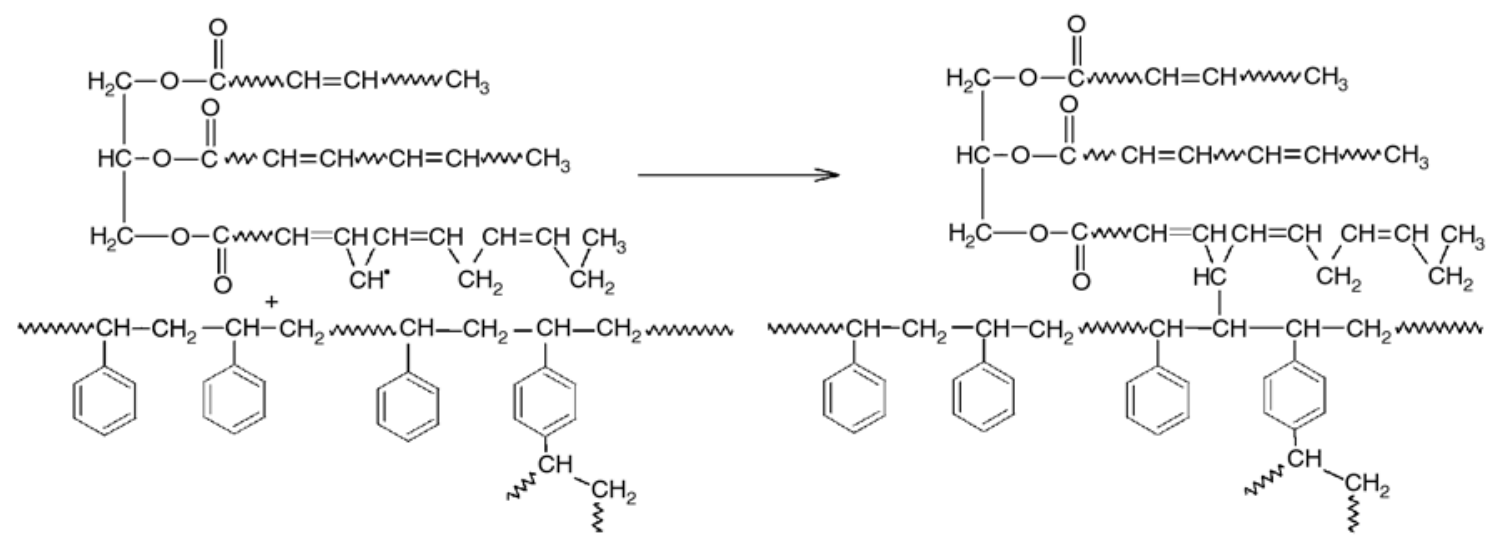

Figure 1. The possible initiation reactions for this free radical process

sists primarily of ST-DVB copolymer. There is a strong possibility of seeing phase separation (macroheterogeneity) between these two phases, leading to some fault or defect-like cracks in the bulk and surface when relatively few dangling vinylic double bonds from the ST-DVB copolymer are available for grafting with the double bonds of the fatty acid chains of the LIN. This condition prevails when a very low amount of DVB $(<14 \%)$ is present in the mixture. Thus, the sample $\mathrm{C}_{8}$, con- taining the least DVB (14\%) exhibits no visible phase separation.

Apparently, the aromatic comonomers (ST and DVB) upon crosslinking strengthen the copolymer chains and thus make the resulting fully cured polymers more viable as structural materials. As noted earlier, when the DVB concentration is not sufficiently high, there is a strong possibility of agglomerating soft and hard phases forming clusters among themselves, leading to macrophase separa- 
tion. The macrophase separation induces cracks in the products, along with the separation of white crosslinked ST-DVB copolymer. With 20\% DVB content $\left(\mathrm{C}_{5}\right.$ of Table 1$)$, both soft and hard phases are still present in the product, but the formation of an oil-grafted ST-DVB copolymer prevents the formation of clusters. Thus, macroheterogeneity reduces to microheterogeneity, which is indicated by the opaque nature of the material.

Based upon the above results, different concentrations of LIN were added to a 3:2 mixture of ST and DVB. It is observed that for a LIN concentration of $30-65 \%\left(\mathrm{C}_{1}-\mathrm{C}_{8}\right)$, the samples are free of cracks. An increase in the DVB content results in the formation of more highly crosslinked copolymers of LIN, further reducing the possibility of macrophase separation.

\subsection{Soxhlet extraction}

The polymer samples were extracted to determine their insoluble content and these results are shown in Table 1. With an increase in the LIN content in the polymeric samples from 30 to $65 \%$, the insoluble content of the samples decreases from 74 to $30 \%$, while the soluble portion increases from 26 to $70 \%$. A plot of the percentage of the LIN vs. the soluble content of the sample is shown in Figure 2. These results indicate that with an increase in the LIN content, the crosslinking densities of the polymeric samples decrease. The polymer samples prepared by the first method have less soluble content as compared to the samples prepared by the second

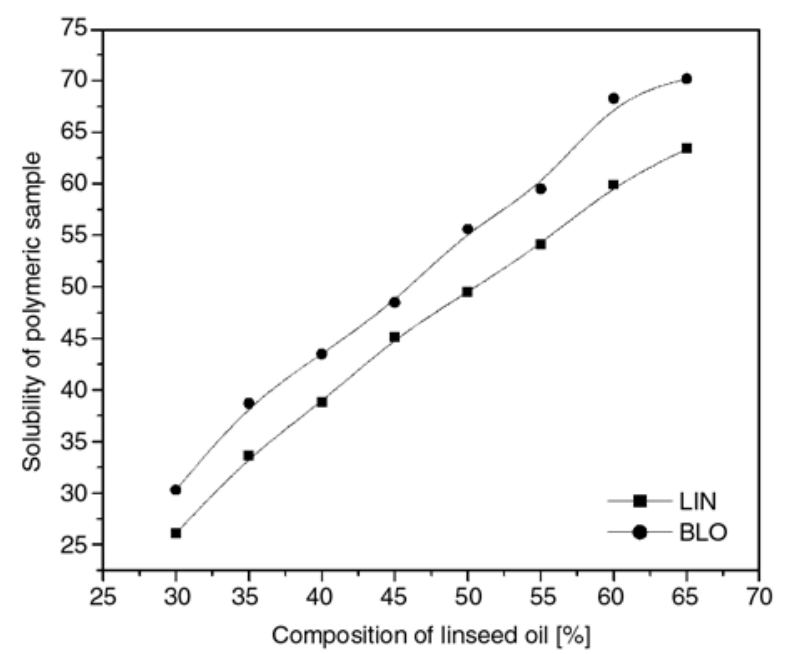

Figure 2. Variation in solubility of the LIN polymers with increasing LIN content method, which indicates that the crosslinking densities of samples prepared by the second method are less than that prepared by the first method. In the second method, the initiator is first allowed to react with the LIN, may cause the formation of peroxylinkages, which subsequently cause the degradation, as well as crosslinking. The presence of the higher soluble contents in the polymers from this second method may be due to this degradation process. It may be caused also because of partial blocking of double bonds with radicals produced by the initiator as well as radical recombination. In such case more active pre-initiated double bonds of the oil are falling out of the following copolymerization process.

\section{3. ${ }^{1} \mathrm{H}$ NMR spectroscopic characterization}

The ${ }^{1} \mathrm{H}$ NMR spectra of ST, DVB, LIN, solvent removed from extractable portion of the polymer (vacuum rota-evaporator) and the soluble extract from the polymeric samples $\mathrm{C}_{5}$ (LIN50-ST30DVB20) and $\mathrm{B}_{5}$ (BLO50-ST30-DVB20) are shown in Figure 3. The extracts from $C_{5}$ and $B_{5}$ are representative of the soluble extracts obtained from all other samples $\left(\mathrm{C}_{1}-\mathrm{C}_{4}\right.$ and $\left.\mathrm{B}_{1}-\mathrm{B}_{4}\right)$. The peaks at $2.8 \mathrm{ppm}$ are due to the methylene $\left(\mathrm{C}_{2}\right)$ protons present in between the two unsaturated $\mathrm{C}=\mathrm{C}$ double bonds of the fatty acid chain. The presence of a similar peak in the DVB is due to the presence of

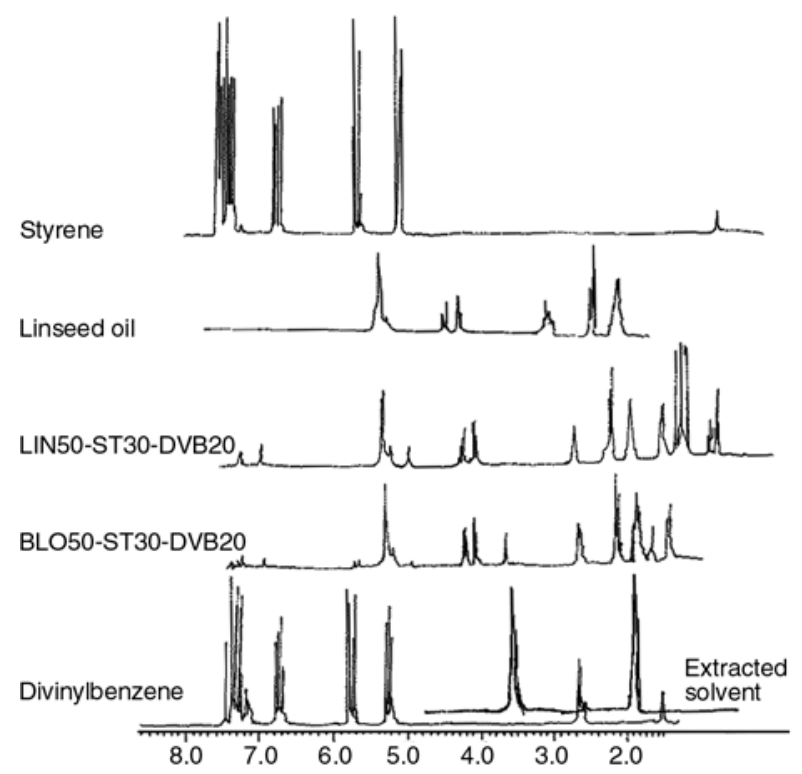

Figure 3. ${ }^{1} \mathrm{H}$ NMR spectra of DVB, extracts of the samples $\mathrm{B}_{5}$ (BLO50-ST30-DVB20) and $\mathrm{C}_{5}$ (LIN50ST30-DVB20), LIN and ST 
methylene protons in the ethylvinylbenzene, which is present to the extent of about $20 \%$ in the DVB. The peaks for the vinylic $(\mathrm{C}=\mathrm{C}-\underline{\mathrm{H}})$ protons of the linseed oil, ST and DVB are present at 5.1$5.8 \mathrm{ppm}$. The peaks at $4.1-4.5 \mathrm{ppm}$ in the soluble extract $\left(\mathrm{C}_{1}-\mathrm{C}_{8}\right.$ and $\left.\mathrm{B}_{1}-\mathrm{B}_{8}\right)$ (samples $\mathrm{C}_{5}$ and $\mathrm{B}_{5}$ are shown in Figure 3) and in LIN are due to the methylene protons $\left(\mathrm{CH}_{2}\right)$ of the glyceride unit. This is a particularly characteristic peak for the LIN oil. It is used in calculating the oil content in the soluble extract of the polymeric material. The aromatic protons of the ST, DVB and the oligomeric portion of these materials are observed between 7.1$7.9 \mathrm{ppm}$. These aromatic peaks are distinctive and are used to calculate the ST and DVB content in the soluble extracts. However, the peak due to the solvent $\mathrm{CDCl}_{3}$ peak, which occurs in the same region at $7.26 \mathrm{ppm}$, has been excluded from all calculations. The solvent removed from the soluble portion by vacuum evaporation is free from any oligomers and the peak is shown in Figure 3. The peak is same as for pure solvent.

The weight percentages of the oil and aromatic components of the different samples are reported in Table 1. The weight percent of the LIN in the soluble extract varies from 86 to $99 \%$ and the weight percent of aromatic components varies from 1 to $14 \%$. The values in parentheses in the Soxhlet results of Table 1 indicate the detailed microcomposition of the polymeric samples. The soluble portion present in the samples helps plasticize the crosslinked insoluble materials. Thus, the insoluble materials mainly determine the properties of the polymeric material. For the samples $\mathrm{C}_{1}-\mathrm{C}_{8}$ and $\mathrm{B}_{1}-\mathrm{B}_{8}$ in Table 1 , the amount of oil decreases in the insoluble fraction, but the decrease is more significant in samples $\mathrm{B}_{1}-\mathrm{B}_{8}$. With the decrease in DVB content from 28 to $14 \%$, the amount of oil in the insoluble portion shows a considerable decrease. This fact is consistent with our hypothesis that the

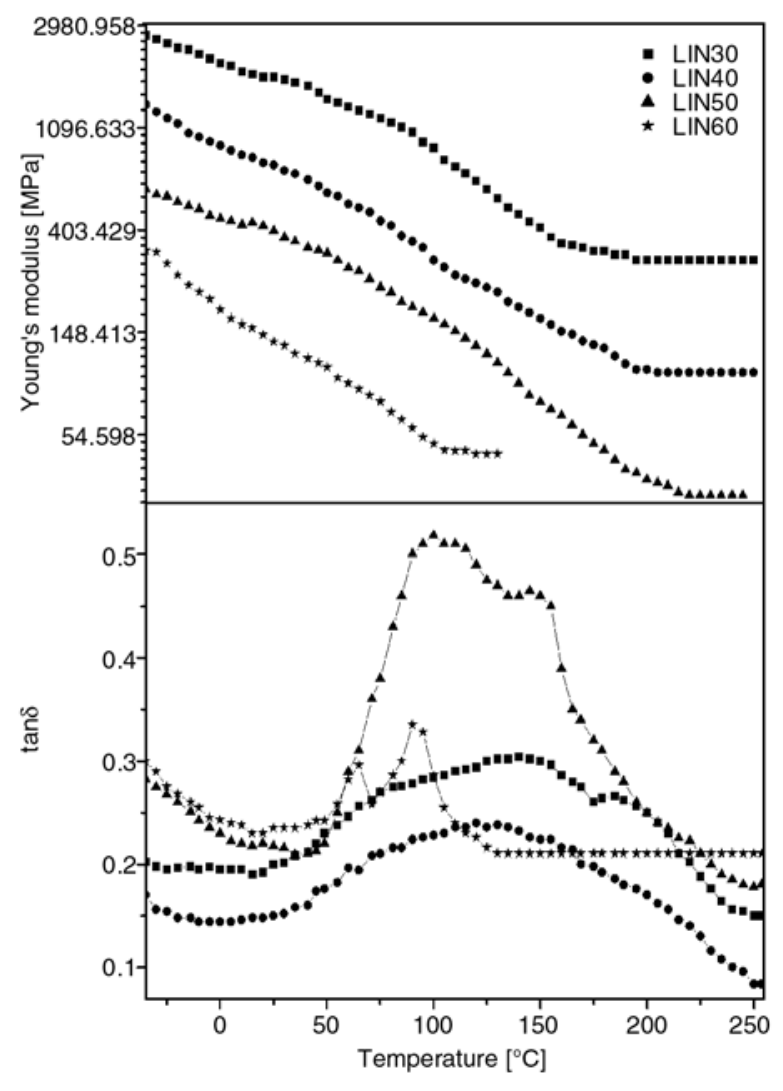

Figure 4. $\tan \delta$ and storage modulus with temperature for LIN polymer samples $\left(\mathrm{C}_{1}, \mathrm{C}_{3}, \mathrm{C}_{5}\right.$, and $\left.\mathrm{C}_{7}\right)$

LIN is grafted into the polymer chain of the ST and DVB copolymer during prolonged heating.

\subsection{Dynamic mechanical analysis}

Figure 4 shows the variation of $\tan \delta$ and storage modulus with temperature for different linseed oil polymer samples $\left(\mathrm{C}_{1}, \mathrm{C}_{3}, \mathrm{C}_{5}\right.$, and $\left.\mathrm{C}_{7}\right)$. The glass transition temperatures were obtained from the tan $\delta$ peaks and the crosslink densities were calculated from the plateau storage moduli using Equation (1). These are listed in Table 2. From the tan $\delta$ plots of Figure 4, the presence of a hump or two peaks in all of the samples except $\mathrm{C}_{1}$ and $\mathrm{C}_{3}$ indicates that there

Table 2. Dynamic mechanical and thermal properties of crosslinked linseed oil-ST-DVB copolymers

\begin{tabular}{|c|c|c|c|c|c|c|c|}
\hline \multirow{2}{*}{ Sample } & \multirow{2}{*}{ Polymer composition } & \multicolumn{2}{|c|}{ DMA results } & \multicolumn{3}{|c|}{ DSC results } & \multirow{2}{*}{$\begin{array}{c}\text { HDT } \\
\text { results }\end{array}$} \\
\hline & & $\mathbf{T}_{\mathbf{g}}\left[{ }^{\circ} \mathbf{C}\right]$ & $v_{e}\left[10^{4} \mathrm{~mol} / \mathrm{m}^{3}\right]$ & $\mathbf{T}_{\mathbf{g}}\left[{ }^{\circ} \mathbf{C}\right]$ & Area [J/gm] & Peak width a & \\
\hline $\mathrm{C}_{1}$ & LIN30-ST42-DVB28 & $141-146$ & 21.00 & 181.28 & 31.70 & 120.57 & 43.6 \\
\hline $\mathrm{C}_{3}$ & LIN40-ST36-DVB24 & 121 & 8.28 & 180.73 & 46.19 & 104.17 & 35.9 \\
\hline $\mathrm{C}_{5}$ & LIN50-ST30-DVB20 & 100 and 146.5 & 6.01 & 178.34 & 62.74 & 99.51 & 31.3 \\
\hline $\mathrm{C}_{7}$ & LIN60-ST24-DVB16 & 66 and 91 & 8.60 & 158.86 & 96.03 & 86.10 & 26.9 \\
\hline $\mathrm{B}_{5}$ & BLO50-ST30-DVB20 & 50.6 and 70.5 & 35.00 & 164.31 & 76.93 & 83.06 & - \\
\hline
\end{tabular}

aDifference between starting and finishing temperature of the peak 
is clearly phase separation between the soft oily phase and the hard aromatic phase. The peaks for sample $\mathrm{C}_{1}$ and $\mathrm{C}_{3}$ get merged due to the broadening of the hump. It was reported that the glass transition temperature peaks for rubbery materials appears in negative region [10]. In present work, the glass transition peaks for all samples are appearing above the room temperature. The crosslink densities of these samples are quite high, which suggests that these polymers should be hard plastics. But from visual inspection, it appears that these samples are neither plastics nor elastic, but to some extent waxy in nature. These observations indicate that these samples are crosslinked as well as degraded (the presence of atmospheric oxygen causes degradation). That is why these samples show high glass transition temperature.

With increase of oil contents in these polymers, it is observed that the strength of these samples is very low, when compared with the polymeric samples from thermal polymerization of conjugated linseed oil reported by Kundu and Larock [10]. The possible explanation is the simultaneous crosslinking and degradation of polymer chains. This leads to the formation of highly crosslinked small polymeric chains giving rise to high $T_{g} \mathrm{~s}$ and crosslink densities $\left(\mathrm{v}_{e}\right)$. The crosslink densities $\left(\mathrm{v}_{e}\right)$ of these samples $\left(\mathrm{C}_{1}, \mathrm{C}_{3}, \mathrm{C}_{5}\right.$, and $\left.\mathrm{C}_{7}\right)$ are plotted in Figure 5. The crosslink density of $\mathrm{C}_{1}$ is the highest and decreases with increasing oil contents upto sample $\mathrm{C}_{5}$. From sample $\mathrm{C}_{5}$ onwards $v_{e}$ start decreasing again which suggest that as the linseed oil contents increased beyond $50 \%$, the degradation of linseed

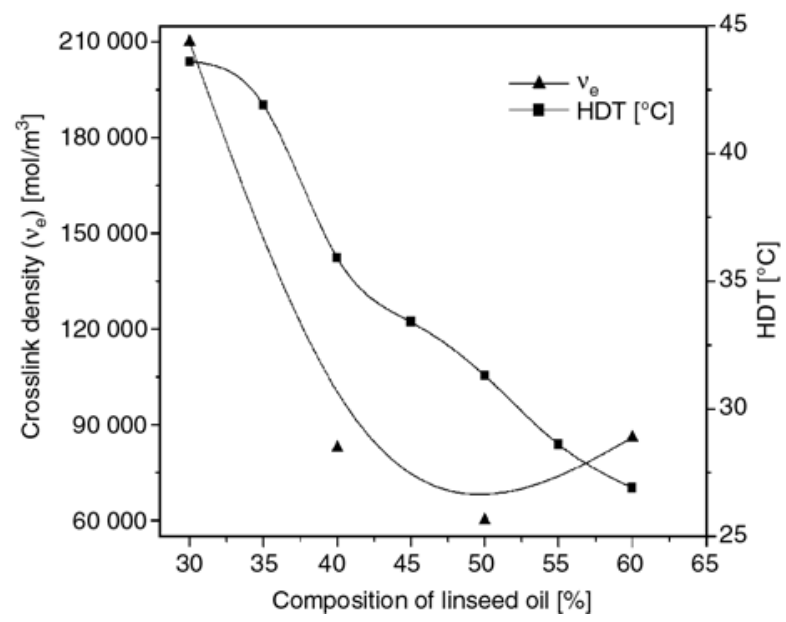

Figure 5. Heat deflection temperatures $\left[{ }^{\circ} \mathrm{C}\right]$ and crosslink density $\left[v_{e}\right]$ with variation in the LIN content oil dominates. This results in highly crosslinked small polymer chains. The samples $\mathrm{B}_{5}$ (not shown in Figure 5) shows highest $v_{e}$ and is more waxy than $\mathrm{C}_{7}$ (LIN 60\%).

In considering the storage modulus plots of these polymers, it is observed that the storage modulus at high temperature $\left(>50^{\circ} \mathrm{C}\right)$ is higher for samples containing less linseed oil and it decreases with increasing oil contents. In samples $\mathrm{C}_{5}$ and $\mathrm{B}_{5}$, sample $\mathrm{B}_{5}$ show high modulus at low temperature $\left(<-5^{\circ} \mathrm{C}\right)$ and sample $\mathrm{C}_{5}$ shows high modulus at temperature higher than $20^{\circ} \mathrm{C}$. This may be due to the reason that, in sample $\mathrm{B}_{5}$, the initiator oligomerizes the oil first and a few peroxy radical left for polymerizing other comonomers. Also, the molecular size of linseed oil is larger than the one of BPO. Thus the BPO treated linseed oil molecules have less reactivity and less diffusablity as compared to BPO. Due to this, the polymerization is lower in sample $\mathrm{B}_{5}$ than $\mathrm{C}_{5}$.

\subsection{Differential scanning calorimetry}

The plots of heat flow $[\mathrm{W} / \mathrm{g}]$ versus temperature $\left[{ }^{\circ} \mathrm{C}\right]$ for different samples are shown in Figure 6. The differential scanning calorimetry results are shown in Table 2. It seems that the polymers show their transitions in a specific temperature range where some chemical reaction may also occur. Thus, the glass transition appears in the range of $164-181^{\circ} \mathrm{C}$ (higher by $40-90^{\circ} \mathrm{C}$ from the transition temperature shown by the samples by dynamic mechanical analysis). But these transitions are

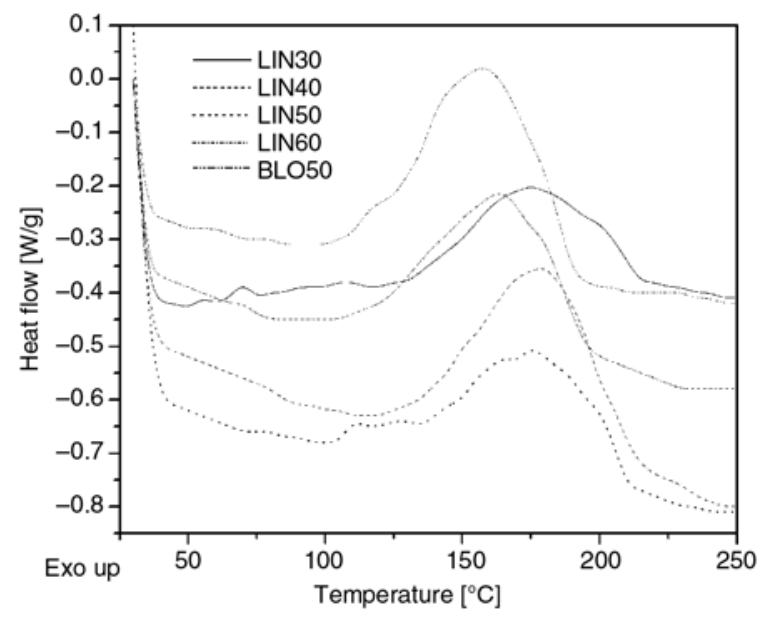

Figure 6. DSC plot using heat flow $[\mathrm{W} / \mathrm{g}]$ versus temperature $\left[{ }^{\circ} \mathrm{C}\right]$ for LIN polymer samples $\left(\mathrm{C}_{1}, \mathrm{C}_{3}, \mathrm{C}_{5}\right.$, $\mathrm{C}_{7}$, and $\mathrm{B}_{5}$ ) 


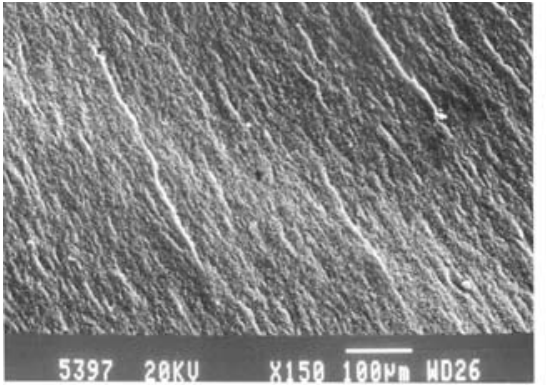

a)

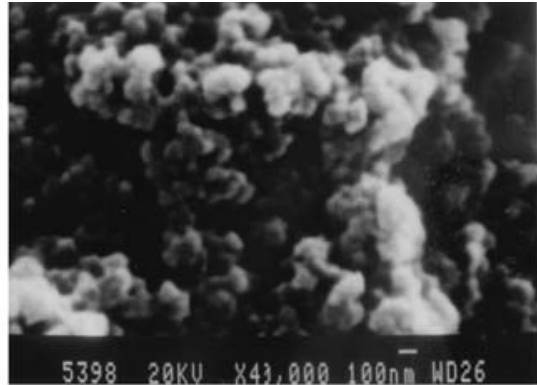

b)

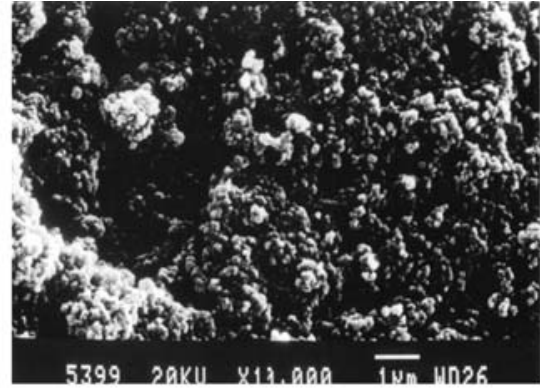

c)

Figure 7. SEM micrographs of the insoluble materials from the sample $\mathrm{C}_{5}$ (LIN50-ST30-DVB20) with different magnifications. (a) Magnification-150×, Scale-100 $\mu \mathrm{m}$, (b) Magnification-40 000×, Scale-100 nm, (c) Magnification$10000 \times$, Scale-1 $\mu \mathrm{m}$

shadowed by exothermic peaks in the range of $164-181^{\circ} \mathrm{C}$, exhibited by the samples. The exothermic peaks are originated due to the possible crosslinking of the polymers initiated from the peroxy linkages formed during the free radical polymerization. In the free radical polymerization, some aerial oxidation occurs during polymerization, resulting in residual peroxy linkages [25].

The sample $\mathrm{C}_{1}$ is hard in nature and it shows a broad peak. As the aromatic component (ST and DVB) decreased, the peak becomes sharper indicating the change in nature of the samples from plastic to waxy. The area of the peak increases with a decrease in peak width. With increase in the oil contents, the content of residual peroxy linkages increases [25]. The presence of more peroxy linkages needs higher energy for its breakage leading to crosslinking of polymers. Thus, the results from Table 2 justify the increase in the peak area. The increasing oil contents resulted in sharper peaks. The $T_{g}$ of sample $\mathrm{C}_{5}$ is higher than that for sample $\mathrm{B}_{5}$, but the peak is observed to be less sharp for sample $C_{5}$ than sample $B_{5}$. This indicates that the sample $\mathrm{B}_{5}$ is waxier.

\subsection{Scanning electron microscopy (SEM) of the insoluble extracts}

The insoluble portion of the samples after extraction with tetrahydrofuran has been used to study the morphological behavior by scanning electron microscopy. The SEM micrographs of all of the samples are very similar and indicate that the material is porous in nature and the pores are evenly distributed throughout the whole matrix. The micrographs of sample $\mathrm{C}_{5}$ are shown as representative of all other samples. Three micrographs of the sample
$\mathrm{C}_{5}$ with different magnification (contains $50 \%$ LIN) are shown in Figure 7. Figure 7a confirms the presence of cracks on the surface of the sample after Soxhlet extraction. Under higher magnifications (Figures $7 \mathrm{~b}$ and $7 \mathrm{c}$ ), the pores are clearly visible, which indicates that the material is porous in nature and, as the ST and DVB content decreases, the material becomes more porous.

\subsection{Heat deflection temperature}

The heat deflection temperatures (HDT) for various samples $\left(\mathrm{C}_{1}-\mathrm{C}_{7}\right)$ are reported in Table 2. In Figure 5, the HDT of the polymeric sample is plotted against the percent of oil. The HDT of sample $\mathrm{C}_{1}$ is the highest $\left(43.6^{\circ} \mathrm{C}\right)$ and that for sample $\mathrm{C}_{7}$ is the lowest $\left(26.9^{\circ} \mathrm{C}\right)$. The higher value of HDT is mainly due to the higher aromatic content present in the polymeric samples. With a decrease in the aromatic content, the HDT of the samples decreases. The HDT for the sample with $65 \%$ oil is not tabulated, since the sample broke during testing due to its softness.

\subsection{Swelling of samples}

The polymeric samples have been tested for swelling in different media. The swelling ratios $\left(q_{v}\right)$ have been determined from the swelling of samples by Equation (3). The swelling ratios of the samples prepared by the first method have been plotted against the percent of oil present in the sample. The graphs for the polymeric materials prepared by both methods are shown in Figure 8. The polymers prepared by the first method $\left(\mathrm{C}_{1}-\mathrm{C}_{8}\right)$ show minimum swelling for saline water and a maximum for tetrahydrofuran. This is due to the fact that tetrahydrofuran is an organic solvent, which can readily 


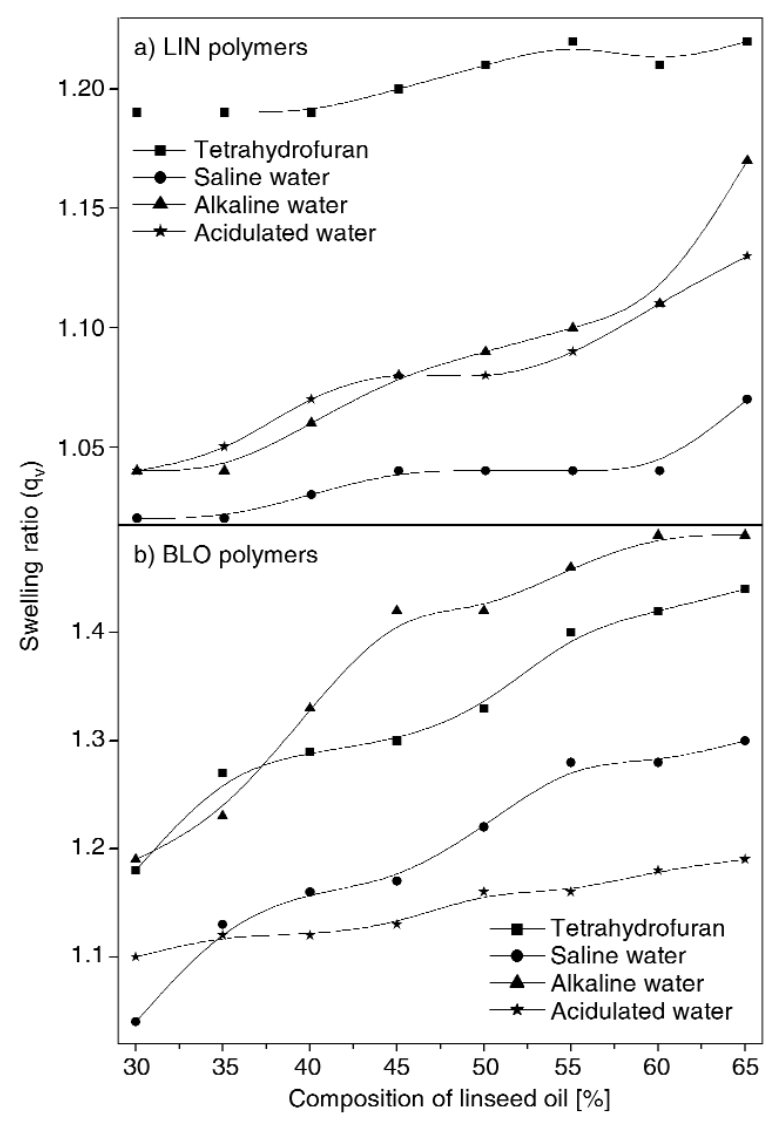

Figure 8. Swelling ratios in various media with variation in (a) the LIN content and (b) the BLO content

diffuse into the polymer network, whereas the other three solutions are aqueous and quite polar in nature and have less penetration into the relatively non-polar polymer and hence show less swelling. For the polymers prepared by the second method $\left(B_{1}-B_{8}\right)$, the swelling is maximum for the alkaline solution and minimum for the acidic solution. Once again, tetrahydrofuran exhibits significant swelling, but even greater swelling is observed in the alkaline solution. This is perhaps due to the fact that initial treatment of the oil by air has resulted in partial oxidation of the oil, which in turn results in alkaline hydrolysis of the resulting polymeric materials, although we have no actual proof of this hypothesis. Due to the presence of oxidized fragments, presumably in the form of carboxylic acids, in the polymeric samples, minimum swelling is observed in acidic solution. When both methods for preparation of the polymers are compared, it is observed that the degree of swelling is greater for the material prepared by the second method. This can be explained by the fact that during polymerization at the higher temperatures, some degradation of the

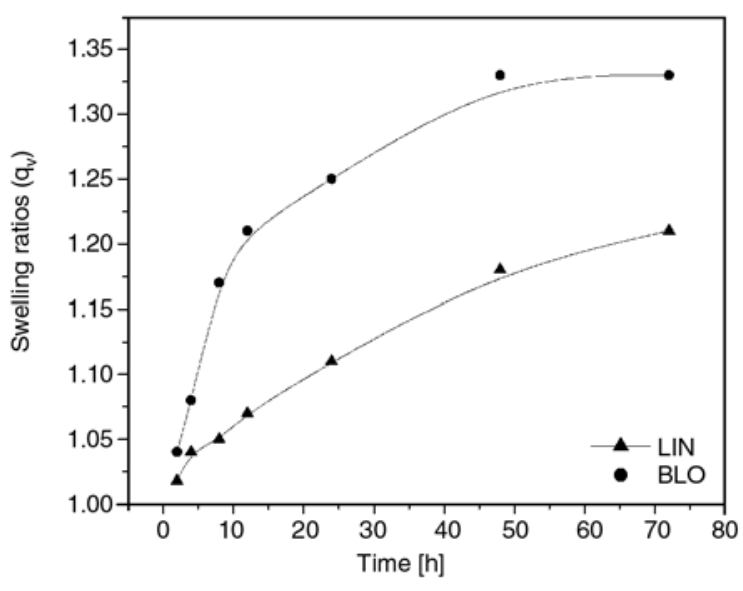

Figure 9. Change in the swelling ratios of $50 \% \mathrm{LIN}\left(\mathrm{C}_{5}\right)$ and BLO $\left(\mathrm{B}_{5}\right)$ samples with time

sample apparently occurs. The polymers prepared by the first method $\left(\mathrm{C}_{1}-\mathrm{C}_{8}\right)$ are quite resistant towards saline water and those prepared by the second method $\left(\mathrm{B}_{1}-\mathrm{B}_{8}\right)$ are resistant towards aqueous acid.

The swelling ratios at different time intervals for tetrahydrofuran for the samples $\mathrm{C}_{5}$ and $\mathrm{B}_{5}$ are shown in Figure 9. Figure 9 represents the time dependence of the swelling ratios. The swelling increases progressively with time. A sharp rise in $q_{v}$ values is observed at the early stages of swelling. After 24 hours, the $q_{v}$ values show little change. This may be explained in terms of the catastrophic rupture of the polymer network due to the internal stress caused by diffusion of the liquid into the polymer network. Sample B5 shows more swelling than sample $\mathrm{C}_{5}$.

\section{Conclusions}

A variety of novel polymers have been synthesized by the free radical graft copolymerization of linseed oil (LIN), ST and DVB in the presence of benzoyl peroxide as an initiator. The copolymerization is performed in a temperature range of $85-130^{\circ} \mathrm{C}$. Various compositions of LIN, ST and DVB start to solidify at $100^{\circ} \mathrm{C}$ and the reaction is completed at $130^{\circ} \mathrm{C}$. The resulting crosslinked polymers have been extracted by tetrahydrofuran in a Soxhlet extractor and are found to contain approximately 30 to $74 \%$ of highly crosslinked materials. ${ }^{1} \mathrm{H}$ NMR spectroscopic analysis indicates that the crosslinked materials are composed of soft oily, as well as hard aromatic domains. The insoluble cross- 
linked materials have been examined under a scanning electron microscope (SEM). The SEM studies reveal the presence of fine pores in the material after extraction and indicate an even distribution of the soluble materials throughout the matrix. The heat deflection temperatures (HDT) of the polymer samples range from 26 to $44^{\circ} \mathrm{C}$. With an increase in the oil content, the softness of the sample increases, leading to higher heat deflection at a lower temperature. The loss tangent and storage modulus have been used to calculate $T_{g}$ and crosslink density of different samples. The $T_{g}$ obtained from DMA for different linseed oil polymer samples ranges from 147 to $66^{\circ} \mathrm{C}$. The crosslink density of samples ranges from 35.0 to $6.01 \cdot 104 \mathrm{~mol} / \mathrm{m}^{3}$. The $T_{g}$ from DSC results ranges from 182 to $158^{\circ} \mathrm{C}$. These results show that the polymer samples prepared from linseed oil are hard and waxy in nature. The samples have been tested for swelling in alkaline, acidic, and brine solutions, as well as in tetrahydrofuran. The polymeric samples $\mathrm{C}_{1}-\mathrm{C}_{8}$ show minimum swelling in saline water and maximum swelling in tetrahydrofuran, while the polymeric samples $\mathrm{B}_{1}-\mathrm{B}_{8}$ show maximum swelling in alkaline solution and a minimum in acidic solution. The polymers prepared show high crosslink density and high transition temperature as show by hard plastics. The visual inspection showed that these samples are not hard plastics and have very little strength. The highly crosslinked materials with lower strength is resulted from the simultaneous oxidative degradation and crosslinking of polymer chains. These observations suggest that these polymers if prepared in anaerobic conditions may results in products with high molecular weight chains.

\section{References}

[1] Conte L. S., Lercker G., Capella P., Catena M.: Linseed oil composition (in Italian). Rivista Italiana delle Sostanze Grasse, 56, 339-342 (1979).

[2] Berglund D. R.: Flax: New uses and demands in. in 'Trends in new crops and new uses.' (eds.: Janick J., Whipkey A.) ASHS Press, Alexandria, 358-360 (2002).

[3] Knörr W., Daute P., Grützmacher R., Höfer R.: Development of new fields of application for linseed oil. Fat Science Technology, 97, 165-169 (1995).

[4] Budwig J.: Flax oil as a true aid against arthritis, heart infarction, cancer and other diseases. Apple Publication, Vancouver (1996).
[5] Motawie A. M., Hassan F. A., Manieh A. A., AboulFetouh M. E., El-Din A. F. J.: Some epoxidized polyurethane and polyester resins based on linseed oil. Journal of Applied Polymer Science, 55, 1725-1732 (1995).

[6] Thames S. F., Hariharan R., Wang Z., Brister E. H., King C. L., Panjanani K. G.: Internally plasticized and low VOC latex compositions and applications thereof. US Patent 6624223, USA (2003).

[7] Tortorello A. J., Montgomery E., Chawla C. P.: Radiation-curable compositions comprising oligomers having an alkyd backbone. US Patent 6638616, USA (2003).

[8] Gultekin M., Beker U., Güner F. S., Erciyes A. T., Yagci Y.: Styrenation of castor oil and linseed oil by macromer method. Macromolecular Materials and Engineering, 283, 15-20 (2000).

[9] Li F., Larock R. C.: Synthesis, structure and properties of new tung oil-styrene-divinylbenzene copolymers prepared by thermal polymerization. Biomacromolecules, 4, 1018-1025 (2003).

[10] Kundu P. P., Larock R. C.: Novel conjugated linseed oil-styrene-divinylbenzene copolymers prepared by thermal polymerization. 1. Effect of monomer concentration on the structure and properties. Biomacromolecules, 6, 797-806 (2005).

[11] Li F., Hanson M. V., Larock R. C.: Soybean oildivinylbenzene thermosetting polymers: Synthesis, structure, properties and their relationships. Polymer, 42, 1567-1579 (2001).

[12] Li F., Larock R. C.: New soybean oil-styrene-divinylbenzene thermosetting copolymers. I. Synthesis and characterization. Journal of Applied Polymer Science, 80, 658-670 (2001).

[13] Li F., Larock R. C.: Thermosetting polymers from cationic copolymerization of tung oil: Synthesis and characterization. Journal of Applied Polymer Science, 78, 1044-1056 (2000).

[14] Li F., Hasjim J., Larock R. C.: Synthesis, structure and thermophysical and mechanical properties of new polymers prepared by the cationic copolymerization of corn, styrene and divinylbenzene. Journal of Applied Polymer Science, 90, 1830-1838 (2003).

[15] Hazer B., Demirel S. I., Borcakli M., Eroglu M. S., Cakmak M., Erman B.: Free radical crosslinking of unsaturated bacterial polyesters obtained from soybean oily acids. Polymer Bulletin, 46, 389-394 (2001).

[16] Wool R. P., Küsefoglu S. H., Palmese G. R., Khot S. N., Zhao R.: High modulus polymers and composites from plant oils. US Patent 6121398, USA (2000).

[17] Khot S. N., Lascala J. J., Can E., Morye S. S., Williams G. I., Palmese G. R., Küsefoglu S. H., Wool R. P.: Development and application of triglyceridebased polymers and composites. Journal of Applied Polymer Science, 82, 703-723 (2001). 
[18] Can E., Küsefoglu S., Wool R. P.: Rigid thermosetting liquid molding resins from renewable resources. I. Copolymers of soyoil monoglycerides with maleic anhydride. Journal of Applied Polymer Science, 81, 69-77 (2001).

[19] Flory P. J.: Principles of polymer chemistry. Cornell University Press, Ithaca (1953).

[20] Nielsen L. E., Landel R. F.: Mechanical properties of polymers and composites. Marcel Dekker, New York (1994).

[21] Kumar R., Shakher C.: Application of digital speckle pattern interferometry and wavelet transform in measurement of transverse vibrations in square plate. Optics and Lasers in Engineering, 42, 585-602 (2004).
[22] Srinivasan P.: Mechanical vibration analysis. Tata McGraw Hill, New Delhi (1990).

[23] Fieldson G. T., Barbari T. A.: The use of F.T.I.R.A.T.R. spectroscopy to characterize penetrant diffusion in polymers. Polymer, 34, 1146-1153 (1993).

[24] Hamurcu E., Baysal B. M.: Interpenetrating polymer networks of poly (dimethylsiloxane). 1. Preparation and characterization. Polymer, 34, 5163-5167 (1993).

[25] Sharma V., Kundu P. P.: Addition polymers from natural oils: A review. Progress in Polymer Science, 31, 983-1008 (2006). 